\title{
Neuraxial Analgesia in Pregnant Hispanic Women: An Assessment of Their Beliefs and Expectations
}

This article was published in the following Dove Press journal:

International Journal of Women's Health

\author{
Basilia Gonzalez' \\ Santiago R Gonzalez ${ }^{2}$ \\ Martha Rojo ${ }^{3}$ \\ Jill Mhyre ${ }^{4}$
}

'Department of Family Medicine, Lifelong Medical Care, Richmond, CA, USA;

${ }^{2}$ Division of Plastic \& Reconstructive Surgery, University of California San Francisco, San Francisco, CA, USA; ${ }^{3}$ College of Nursing, University of Arkansas for Medical Sciences, Little Rock, AR, USA; ${ }^{4}$ Department of Anesthesiology, University of Arkansas for Medical Sciences, Little Rock, AR, USA
Correspondence: Santiago R Gonzalez Division of Plastic \& Reconstructive Surgery, University of California San Francisco, 513 Parnassus Ave, San Francisco, CA 94117, USA

Email Santiago.gonzalez2@ucsf.edu
Background: The presence of racial/ethnic disparities in the use of neuraxial labor analgesia for childbirth has been previously described. The purpose of this study was to assess the childbirth pain management beliefs among a small sample of pregnant Hispanic women and to evaluate the Spanish translation accuracy of the Childbirth Pain Scale (CPBS).

Methods: To collect data, we interviewed 20 pregnant Spanish-speaking women using an interview guide, a demographic datasheet, and the CPBS a 15-item survey. Interviews were transcribed verbatim, translated, and uploaded to ethnograph v6. Descriptive statistics and thematic analysis were used to analyze the data.

Results: Most of the participants were from Mexico $(n=16)$ and Central America $(n=4)$, mean age was 28.3 , and all $(n=20)$ spoke Spanish as their primary language. In this sample, $80 \%$ of nulliparous and $100 \%$ of multiparous women saw pain as having a positive role in delivery. Four major themes emerged from the data: Theme 1: Normalcy of childbirth pain (pain is good), Theme 2: Availability and role of pain medication, Theme 3: Naturalistic strategies to endure pain, and Theme 4: Fear of the unknown/childbirth process. In this sample, 18 of 20 women stated they did not want epidural analgesia unless medically indicated. During labor and delivery $100 \%$ of nulliparous and $25 \%$ of multiparas chose to receive epidural analgesia. No changes were requested by the participants regarding the translation of the CPBS.

Conclusion: Childbirth pain was seen as a valuable component of the birthing process. The majority of participants believed pain medication should be avoided unless medically necessary. These results suggest that racial/ethnic disparities in the use of epidural analgesia may partially reflect patient beliefs and preferences. It is crucial to be aware of these differences to optimize shared decision-making for women in this vulnerable patient population.

Keywords: pain management, neuraxial analgesia, racial disparities, pregnancy, childbirth, Hispanic

\section{Introduction}

Racial and ethnic disparities in the treatment of pain have been well described in the literature. ${ }^{1-10}$ These disparities have been strongly linked to the use of neuraxial analgesia for alleviating pain during labor, ${ }^{11,12}$ and specific studies have described the presence of such disparities in pregnant Hispanic women. ${ }^{13-15}$ Factors such as antenatal planning, ${ }^{16}$ socioeconomic status, ${ }^{17}$ maternal age, ${ }^{18}$ and level of education ${ }^{19}$ have been associated with differences in the use of neuraxial analgesia in labor.

Although quantitative demographic and socioeconomic factors have been linked to differences in the use of neuraxial analgesia among Hispanic women, factors 
such as patients' preferences and beliefs may also play a role in treatment decisions and final outcomes. However, patients' beliefs about childbirth pain and preferences regarding pain management during the birthing process have not been described in the literature.

Previously published studies have described Hispanic women's beliefs about childbirth. A study by Orejuela et al, showed that Hispanic women are more likely to view childbirth pain as a duty of motherhood. ${ }^{20}$ In addition, Hispanic patients are prone to prefer noninvasive medical treatments, and to have negative attitudes towards pain medications, opting for pain medications only as a "last resort." ${ }^{, 1,22}$ Despite the abundant literature describing differences in racial/ethnic beliefs, to date, there are no studies that have quantified the effect of those preferences and beliefs in the use of analgesia during childbirth.

The purpose of this study was to investigate the extent to which the disparities experienced by Hispanic women in the use of neuraxial analgesia reflect preferences and beliefs about the role of childbirth pain. An additional aim was to evaluate the clarity and accuracy translation of the Childbirth Pain Beliefs scale (CPBS) in Spanishspeaking pregnant women. This scale has been used to assess the pain beliefs in White women but not in Spanishspeaking pregnant women.

\section{Methods}

Approval for this study was obtained from the Institutional Review Board (IRB) at the University of Arkansas for Medical Sciences (UAMS). Twenty pregnant Spanish-speaking women were recruited from the UAMS Women's Clinic from the following two subsets: multiparous $(n=14)$ and nulliparous $(n=6)$. Clinic nurses screened participants to ensure they met the following inclusion criteria: 1) older than 18 years of age, 2) $\geq 20$ weeks gestational age, 3) pregnant with a healthy singleton fetus, and 4) anticipated vaginal birth. After introducing the study, verbal informed consent was obtained. During the informed consent process, patients agreed to have their medical records accessed. Verbal informed consent was approved by the IRB at the University of Arkansas for Medical Sciences, and this study was conducted in accordance with the Declaration of Helsinki. Data was collected through the following methods: 1) face-to-face interviews, 2) the CPBS 15-item survey, a 3) socio-demographic data sheet (4 questions), and a 4) participant characteristics sheet (Ante-partum: 6 questions, Intrapartum: 7 questions). A semi-structured interview guide was used for the face-to-face interviews, which included six open-ended questions for nulliparous, and nine open-ended questions for multiparous participants (Appendix IIA and IIB). The Interviews and CPBS were conducted by two medical students, both fluent in the patient's preferred language, either English or Spanish. All interviews were conducted in a private conference room, were audio-recorded, transcribed in Spanish, translated to English, and uploaded to ethnograph v6 for data analysis. Transcripts were reviewed independently by two of the authors, data were organized, and after initial coding, a coded book was developed. After coding occurred, then codes were clustered into themes by the two authors. All codes and themes were discussed among the four authors and any discrepancies were discussed until consensus was reached. ${ }^{24}$ Microsoft Excel was used to calculate the descriptive statistics from the socio-demographic data collected.

The CPBS is a 15-item scale that measures four domains of pain beliefs: 1) the beneficial effects of pain; 2) the detrimental effects of pain; 3) the utility of medication to treat pain; and 4) pain tolerance (Appendix IA and IB). The CPBS was developed using content analysis of both childbirth education materials from a range of birthing philosophies, focus groups, and individual interviews. Items were tested in a large survey, and factor analysis was used to identify clusters of items that reflected four salient themes. The CPBS was translated to Spanish, and back-translated to English. It was then administered to participants in Spanish. These techniques were used to establish semantic equivalency in translation and to ensure that the integrity of the data was not lost during translation. ${ }^{23}$ The CPBS items were recorded using a 5-point Likert scale questionnaire ranging from strongly disagree to strongly agree. Each item was read to the participants and they selected the answer that best fits their opinion.

Following the completion of the CPBS, participants were asked to describe their thoughts about each item on the scale. Lastly, the participants were asked for any essential concepts about childbirth pain that were missing from the CPBS.

To illustrate potential links between the participant's responses and their actual behavior during their labor admission, data from their electronic medical records were queried.

Factors such as the indication for admission, type of analgesia used during labor, estimated hours from admission to any placement of neuraxial analgesia, mode of delivery, 
age at admission, gestational age at delivery, and the usage of other pain medications during delivery were recorded.

\section{Results}

\section{Patient Demographics}

Most of the participants were from Mexico $(n=16)$, Guatemala $(\mathrm{n}=2)$, Dominican Republic $(\mathrm{n}=1)$, and Honduras $(\mathrm{n}=1)$. The mean age of participants was $28.3(\mathrm{~s}=6.3)$. All of the $(\mathrm{n}=20)$ women spoke Spanish as their primary language. Two of the participants spoke dialects of Guatemalan origin, in addition to Spanish. Of the 20 participants, 18 preferred for all medical communication to be in Spanish and two participants were confident conversing in both English and Spanish. The mean number of years in the United States was $8.2(\mathrm{~s}=5.6)$. The highest level of education completed by participants were: less than high school $(n=8)$, high school diploma $(n=10)$, some college $(n=1)$, bachelor's degree $(n=1)$, and master's degree $(n=1)$. The patient demographics and personal characteristics can be seen in Tables 1 and 2 .

\section{Qualitative Thematic Analysis}

The analysis identified four main themes. See below for illustrative quotes and themes.
Table I Participant Demographics

\begin{tabular}{|l|l|}
\hline Characteristics & $\mathbf{( N = 2 0 )}$ \\
\hline Age (years), mean, (SD) & $28.3(6.2)$ \\
\hline Education & \\
Less than high school & 7 \\
High school & 10 \\
Some college & $\mathrm{I}$ \\
College graduate & $\mathrm{I}$ \\
Advanced degree & $\mathrm{I}$ \\
\hline Country of origin & \\
Mexico & 16 \\
Guatemala* & 2 \\
Honduras & $\mathrm{I}$ \\
Dominican Republic & $\mathrm{I}$ \\
\hline Time in USA (years) & $0.5-20$ \\
\hline
\end{tabular}

Notes: *Two patients spoke dialects from Guatemala: One patient spoke 2 dialects in addition to Spanish, another patient spoke I dialect in addition to Spanish. All other patients spoke Spanish as their primary language.

Theme I: Normalcy of Childbirth Pain (Pain is Good) In this sample, all of the women (nulliparous and multiparous) mentioned at least one positive attribute of childbirth pain. In general, women believed that the childbirth pain is associated with creating life and therefore pain was considered a necessary part of the birthing process. Some

Table 2 Individual Characteristics of Participants During Pre-Partum Interview

\begin{tabular}{|c|c|c|c|c|c|c|}
\hline ID & $\begin{array}{l}\text { Age } \\
\text { (Years) }\end{array}$ & $\begin{array}{l}\text { Country of } \\
\text { Origin }\end{array}$ & $\begin{array}{l}\text { Time in USA } \\
\text { (Years) }\end{array}$ & Education & $\mathbf{G} / \mathbf{P} *$ & $\begin{array}{l}\text { Gestational Age } \\
\text { (Weeks, Days) }\end{array}$ \\
\hline I & 22 & Mexico & 20 & High school & G4P20I2 & $28 w 4 d$ \\
\hline 2 & 26 & Mexico & 4 & College & G3PI0II & $24 w 5 d$ \\
\hline 3 & 28 & Mexico & 8 & High school & G8P5024 & $37 w 5 d$ \\
\hline 4 & 33 & Mexico & 12 & High school & G3P2002 & $39 w 1 d$ \\
\hline 5 & 39 & Mexico & 19 & College & G5P4004 & $35 w 0 d$ \\
\hline 6 & 27 & Mexico & 10 & 6th grade & G5P30I3 & $27 w 1 d$ \\
\hline 7 & 23 & Mexico & 2 & 6th grade & GIPO & $35 w 5 d$ \\
\hline 8 & 43 & Mexico & 3 & Master's & G3P0020 & $20 w 0 d$ \\
\hline 9 & 24 & Mexico & 6 & 6th grade & GIPO & $29 w 6 d$ \\
\hline 10 & 29 & Mexico & 12 & High school & G4P20I2 & $38 w 0 d$ \\
\hline 11 & 20 & Mexico & 4 & High school & GIPO & $37 w 0 d$ \\
\hline 12 & 22 & Guatemala** & 4 & 8th grade & G2P00I0 & $39 w 5 d$ \\
\hline 13 & 26 & Mexico & 5 & High school & G3P2002 & $36 w l d$ \\
\hline 14 & 32 & Mexico & 0.5 & 6th grade & G2PI00I & $26 w 5 d$ \\
\hline 15 & 32 & Mexico & 11 & High school & G4P20I2 & $36 w l d$ \\
\hline 16 & 27 & Dom. Republic & 9 & High school & G3P0020 & $29 w 0 d$ \\
\hline 17 & 38 & Guatemala** & 2 & 2nd grade & G6P5005 & $39 w 0 d$ \\
\hline 18 & 19 & Honduras & 4 & High school & G2PI00I & $37 w 2 d$ \\
\hline 19 & 27 & Mexico & 14 & High school & G2PI00I & $28 w 6 d$ \\
\hline 20 & 29 & Mexico & 14 & 6th grade & G2PI00I & $36 w 6 d$ \\
\hline
\end{tabular}

Notes: **Both patients from Guatemala spoke dialects of Guatemalan origin in addition to speaking Spanish. *Term, preterm, abortion, living. 
Box I Theme I - Normalcy of Childbirth Pain (Pain is Good)

- "Well, the pain means you're giving life to a human being, and after the pain you have your reward because you have your baby."

- "Well, I've never felt it but I imagine pain is just part of the process and I was told by the women in my family that birth pain is part of giving life."

- "I believe that pain is natural, it is part of the process, pain helps you to push when the contractions come so pain is good."

- "Pain is nature's way of making me feel how significant and important giving birth is."

women viewed childbirth pain as positive, and they were willing to endure it with pride. Other women believe that childbirth pain serves as a warning that tells them that the baby is coming. They also believe that the pain prepares them to push during the contractions, and helps them to breathe during painful contractions. To see participant quotes illustrating this theme see Box 1.

\section{Theme 2: Availability and Role of Pain Medication}

Most of the women (nulliparous and multiparous) were aware that pain medication was a viable option during childbirth; but only two affirmed that they would use epidural analgesia to control childbirth pain. In this sample, most of the women had concerns about the safety of epidural analgesia, and they were worried about its side effects and how those side effects would affect their unborn child. Interestingly, multiparous women who had previous experience with epidural analgesia described their decision-making as strongly influenced by provider recommendations, especially related to the welfare of the newborn. To see participant quotes illustrating this theme see Box 2.

Box 2 Theme 2 - Availability and Role of Pain Medication

- "This time I am not going to get the epidural, I worry about the side effects of the epidural that is why this time I do not want it placed. Ever since I had it placed my back hurts, especially when the weather is cold, and my back did not hurt before the epidural."

- "I worry about the side effects of the epidural. Does it hurt my baby some people say that it makes the baby too sleepy I don't know the side effects but I worry about the side effect I will ask the doctor if I really need it."

- "In regards to the epidural-well, I am going to try not to have it placed, but I am going to tell them that in case I need it, especially if my baby is in trouble, then maybe I can have it placed, but I will ask the doctor."

- "I don't want the epidural but if the doctor tells me that I need it for some reason for the safety of my baby I will do it but I don't want it unless I really need it".
Box 3 Theme 3 - Naturalistic Strategies to Endure Pain

- "As I did in the previous ones, relax and breathe. I already have experiences as this is the third one."

- "Well pray, breathe, and endure the pain. It is best to wait until the baby is ready to start to push."

- "Well just breathe and squeeze my husband's hand and try to be calm."

\section{Theme 3: Naturalistic Strategies to Endure Pain}

An important theme that emerged from theme 2 was that women in this sample identified non-pharmacologic strategies to aid them with their pain. These women were aware of pain during childbirth and they had identified strategies to control their pain during the childbirth process, including breathing, walking, and relaxation exercises. To see participant quotes illustrating this theme see Box 3 .

\section{Theme 4: Fear of the Unknown/Childbirth Process} Most of the women in this sample perceived childbirth pain as a normal phenomenon; they were not afraid of childbirth pain but they were afraid and felt anxious regarding the childbirth process. They voiced concerns about the unknown and their inability to control the outcome. Even those women with previous experience with childbirth were concerned about the possibility of something going wrong. To see participant quotes illustrating this theme see Box 4.

\section{Clarity of the CPBS Scale}

Based on the interviews, all participants verbalized understanding and confirmed that they interpreted the items in the CPBS as intended. They also expressed that the items were clear, easy to understand, and that the translation was accurate based on their understanding of the written text. None of the women requested modifications to the scale.

Box 4 Theme 4 - Fear of the Unknown/Childbirth Process

- "Well I was afraid because I did not know exactly what was going to happen"

- "I was scared because I did not know how it was going to be, they asked me if I wanted a normal birth or cesarean, I was in labor for I day but in the end it was natural."

- "I felt nervous because I did not know what it was going to be like, the clinic gave me information and the nurses and doctors told me what it was going to be. I felt more or less ready." 


\section{Labor Admission}

During their labor admission, ten 10 participants received epidural analgesia, four received combined spinal epidural analgesia, and six multiparas delivered vaginally without neuraxial analgesia. For those who received neuraxial analgesia, the duration of labor between admission and block placement ranged between 1 hour and 20.75 hours. The modes of delivery included: standard vaginal delivery $(\mathrm{n}=17)$, low-transverse cesarean delivery $(\mathrm{n}=2)$, and instrumental vaginal delivery $(n=1)$. The patient characteristics at the time of admission, during labor, and during delivery can be seen in Table 3 .

\section{Discussion}

The perspective that pain is a normal and useful part of childbirth has been previously described in the literature. This perspective has been described as the "working with pain" paradigm. ${ }^{25-28}$ This set of beliefs promotes the acceptance of pain as a normal physiological response to childbirth, which is based on the release of hormones and neurotransmitters that facilitate labor by enhancing focus, pain endurance, and strength of contractions. ${ }^{29-31}$ The "working with pain" paradigm was replaced with the "pain relief paradigm" following significant advances in anesthesia in the mid-19th century. ${ }^{32}$ This paradigm promoted the use of pharmacological pain relief during labor, and became the norm in high-income countries. ${ }^{32,33}$ Despite the widespread use of anesthesia, the belief that pain is a positive component of childbirth is not unique to Hispanic women. A variety of observational studies involving diverse groups of women have reported that women indicate a sense of accomplishment after undergoing childbirth pain without the use of pain medication. ${ }^{34-38}$

This study of Hispanic pregnant women identified four main themes that were consistent with the CPBS and with previous literature. Both the nulliparous and multiparous women in this study strongly endorsed the concept that pain is a natural and important part of the birthing process. All participants were aware of analgesic options and were willing to utilize epidural analgesia on the basis of provider recommendations, particularly to ensure the safety of their newborn. Finally, their primary fear was not of pain, but rather a fear of the unknown and risk of any complications during the birthing process.

In this study, 18 of 20 women stated that they did not want epidural analgesia unless medically indicated. During labor and delivery, $100 \%$ of nulliparas and $25 \%$ of

Table 3 Patient Characteristics at the Time of Admission, During Labor, and Delivery

\begin{tabular}{|c|c|c|c|c|c|c|c|}
\hline ID & Age (Yrs.) G/P & \multicolumn{2}{|c|}{$\begin{array}{l}\text { Gestational } \\
\text { Age }\end{array}$} & $\begin{array}{l}\text { Admission } \\
\text { Indication* }\end{array}$ & $\begin{array}{l}\text { Anesthesia } \\
\text { Type** }\end{array}$ & $\begin{array}{l}\text { Time to } \\
\text { Anesthesia (Hrs.) }\end{array}$ & $\begin{array}{l}\text { Mode of } \\
\text { Delivery*** }\end{array}$ \\
\hline I & 23 & G4P30I3 & $40 \mathrm{wld}$ & SOL & None & & SVD \\
\hline 2 & 26 & G3P20I2 & $39 w 5 d$ & SOL & CSE & $1: 59$ & SVD \\
\hline 3 & 28 & G8P5025 & $38 w 5 d$ & SOL & Epidural & $\mathrm{I}: 40$ & SVD \\
\hline 4 & 33 & G3P3003 & $39 w 3 d$ & SOL & None & & SVD \\
\hline 5 & 40 & G5P5005 & $38 w 2 d$ & SOL & Epidural & $4: 20$ & SVD \\
\hline 6 & 27 & G5P40I4 & $38 w 4 d$ & SOL & None & & SVD \\
\hline 7 & 23 & GIPI & $38 w / d$ & IOL: GTN & CSE & $20: 45$ & $1^{\circ}$ LTCS \\
\hline 8 & 43 & G3PI02I & 39 wld & IOL & Epidural & $5: 20$ & $1^{\circ}$ LTCS \\
\hline 9 & 25 & GIPI & 37 wld & IOL: GTN & Epidural & $13: 25$ & SVD \\
\hline 10 & 29 & G4P30I3 & $39 w 2 d$ & SOL & None & & SVD \\
\hline II & 21 & GIPI & $39 w 0 d$ & IOL: GTN & Epidural ${ }^{* * * *}$ & $14: 00$ & SVD \\
\hline 12 & 22 & G2PIOII & $40 w 0 d$ & SOL & None & & SVD \\
\hline 13 & 26 & G3P3003 & $40 w 5 d$ & IOL & Epidural & $5: 45$ & SVD \\
\hline 14 & 32 & G2P2002 & $38 w 6 d$ & SOL & Epidural & $\mathrm{I}: 00$ & SVD \\
\hline 15 & 33 & G4P30I3 & $39 w 3 d$ & IOL & CSE & $4: 35$ & SVD \\
\hline 16 & 27 & G3PI02I & $40 w 2 d$ & SOL & CSE & $3: 00$ & Vac. Ass. \\
\hline 17 & 38 & G6P6006 & $39 w 6 d$ & SOL & Epidural & $\mathrm{I}: 00$ & SVD \\
\hline 18 & 19 & G2P2002 & $40 \mathrm{wld}$ & SOL & Epidural & $5: 10$ & SVD \\
\hline 19 & 27 & G2P2002 & 4 Iw0d & SOL & Epidural & $3: 00$ & SVD \\
\hline 20 & 29 & G2P2002 & 4 Iwld & IOL & None & & SVD \\
\hline
\end{tabular}

Notes: *SOL=spontaneous onset of labor, IOL=induction of labor, IOL: GTN-induction of labor for gestational hypertension at term. $* * 0=$ no anesthesia, CSE=combined spinal epidural. ***SVD=spontaneous vaginal delivery, Primary lower transverse cesarean section, vacuum assistance. *****atient received Fentanyl $100 \mathrm{mcg} \times 2$ as well. 
multiparas who intended to avoid neuraxial analgesia, did receive it during labor. It is unclear what factors played a role in the decision to receive epidural analgesia, and postpartum interviews were not conducted to explore these reasons. Factors could include: provider recommendation, level of pain, duration of labor, labor complications, fatigue, or role of support system (doula, partner, other family members, friends). We can, however, assume that 4 of the 14 women who received combined spinal epidural analgesia did so due to unbearable pain as it is only selected at the UAMS labor and delivery unit in cases of extreme pain for faster analgesic onset. It is also not unusual for nulliparous women to find the pain experience greater than expected, and decision-making has been shown to shift in labor. ${ }^{39,40}$ Studies about the "expectation-experience gap" reveal that women who plan to avoid pain relief during childbirth underestimate the pain they will experience. $^{41}$ It is possible that tailored childbirth education could enhance preparation prior to childbirth. ${ }^{41}$ This may help explain why there was a lack of association between the survey responses in nulliparous women and their ultimate decision to use neuraxial pain management. A future longitudinal study could explore the disconnect between antepartum childbirth pain beliefs and use of epidural analgesia, and would ideally include postpartum interviews with the patient, providers, significant others and anyone else who played a role in the decisionmaking process.

An additional cause for the discrepancy between survey responses and the use of anesthesia by the participants may be the presence of a language barrier. Although most of the women in this sample did not speak English, the UAMS labor and delivery unit utilizes a team of certified Spanish interpreters available around the clock and backed up by a phone-based service. Nevertheless, it remains possible that failures in communication influenced decision-making to utilize neuraxial analgesia. Provider preference may have also played a role in the outcomes of this study. ${ }^{12,20}$ At our facility, anesthesia services are always available, with the expectation that neuraxial blockade is achieved within 1 hour of request. Each woman is evaluated by an anesthesiologist at the time of hospital admission, at which time, several birthing scenarios are discussed alongside analgesic and anesthetic options as part of the informed consent process; all informed consent discussions are completed with a certified interpreter.
Neuraxial blockade is recommended by anesthesiologists only when medically indicated (eg, in anticipation of likely cesarean delivery). That being said, nursing and obstetric staff may suggest neuraxial analgesia upon patient request for pain relief or patient duress.

An important limitation of this study was the use of a survey tool that is not yet validated. The CPBS was developed using English-language patient education materials and focused groups of English-speaking participants. The data to validate the CPBS scale has been collected and is in the process of publication. Only two of the four items held strong salience for the participants in the current study. Conversely, fear of the unknown in childbirth, but not necessarily childbirth pain, emerged as an important theme for this vulnerable population. In addition, the study captured data from a small population of Spanish-speaking women living in a single United States territory, of whom $80 \%$ were from Mexico. Latinas are a diverse population that include Afro-Caribbeans, Central and South Americans as well as Europeans, and cultural beliefs about birth likely vary within each of these groups, and on the basis of life experiences, socio-economic status, and current environment. It is important to note that the interviews were conducted by medical students to ensure a low risk of the power imbalance between interviewers and participants. Hierarchical relationships could lead to answers that the respondent believes are expected by the interviewer. To help prevent any bias in responses, interviews were conducted in the patient's preferred language, interviewers made sure to not deviate from the questionnaire as it was written, and it was made clear through informed consent that this study was focused on learning about the beliefs pregnant Hispanic women have about pain and pain management.

Our study demonstrates that Hispanic women are not afraid of childbirth pain but are instead anxious about the birthing process or the possibility of unknown complications. The women in this study verbalized understanding and acceptance that childbirth is painful, and they have developed a concept of childbirth pain that is necessary for this process. Many are open to medications to relieve childbirth pain if recommended by the medical team, particularly when it is perceived to enhance the safety of their fetus. Most of the women during the interview preferred not to use epidural analgesia during the labor and delivery however some women opted to take the epidural. It is unclear what prompted women to opt for epidural analgesia when it had not been planned; a postpartum interview was 
not conducted. A future study should be considered to measure antepartum childbirth pain beliefs, and to explore the influence of those beliefs on decision-making in labor, and processing postpartum. Preference to avoid epidural analgesia is consistent with reports of educational programs designed to increase awareness of pain management options for childbirth pain that led to increases in the proportion of Hispanic women who choose to receive neuraxial analgesia. $^{42}$ The results of our study also support the literature describing the phenomenon that Hispanic women are less likely to expect the need for neuraxial analgesia, but that actual utilization rates approach those of other populations when the service is available. ${ }^{13}$ As health care providers, it is crucial for us to fully explain the risk and benefits of the available treatment options with the appropriate language assistance, to be aware of potential cultural beliefs that may differ from modern western practice, and to respect such differences to ensure we provide compassionate, welcoming, and high-quality care for Hispanic pregnant women and their families.

\section{Disclosure}

The authors report no conflicts of interest in this work.

\section{References}

1. Cleeland CS, Gonin R, Baez L, Loehrer P, Pandya KJ. Pain and treatment of pain in minority patients with cancer. The Eastern Cooperative Oncology Group Minority Outpatient Pain Study. Ann Intern Med. 1997;127(9):813-816. doi:10.7326/0003-4819-1279-199711010-00006

2. Hwang U, Richardson LD, Harris B, Morrison RS. The quality of emergency department pain care for older adult patients: geriatric ed pain care and associated factors. $J$ Am Geriatr Soc. 2010;58 (11):2122-2128. doi:10.1111/j.1532-5415.2010.03152.x

3. Heins JK, Heins A, Grammas M, Costello M, Huang K, Mishra S. Disparities in analgesia and opioid prescribing practices for patients with musculoskeletal pain in the emergency department. $J$ Emerg Nurs. 2006;32(3):219-224. doi:10.1016/j.jen.2006.01.010

4. Richardson LD, Babcock Irvin C, Tamayo-Sarver JH. Racial and ethnic disparities in the clinical practice of emergency medicine. Acad Emerg Med. 2003;10(11):1184-1188. doi:10.1197/S10696563(03)00487-1

5. Todd KH, Samaroo N, Hoffman JR. Ethnicity as a risk factor for inadequate emergency department analgesia. JAMA. 1993;269 (12):1537-1539. doi:10.1001/jama.1993.03500120075029

6. Groenewald CB, Rabbitts JA, Hansen EE, Palermo TM. Racial differences in opioid prescribing for children in the United States. PAIN. 2018;159(10):2050-2057. doi:10.1097/j.pain.0000000000001290

7. Harrison JM, Lagisetty P, Sites BD, Guo C, Davis MA. Trends in prescription pain medication use by race/ethnicity among US adults with noncancer pain, 2000- 2015. Am J Public Health. 2018;108 (6):788-790. doi:10.2105/AJPH.2018.304349

8. Beaudoin FL, Gutman R, Zhai W, et al. Racial differences in presentations and predictors of acute pain after motor vehicle collision. PAIN. 2018;159(6):1056-1063. doi:10.1097/j.pain.0000000000001186
9. Rasu RS, Knell ME. Determinants of opioid prescribing for nonmalignant chronic pain in US outpatient settings. Pain Med. 2018;19 (3):524-532. doi:10.1093/pm/pnx025

10. Singhal A, Tien -Y-Y, Hsia RY. Racial-ethnic disparities in opioid prescriptions at emergency department visits for conditions commonly associated with prescription drug abuse. Seedat S, ed. PLoS One. 2016;11(8):e0159224. doi:10.1371/journal.pone.0159224

11. Rust G, Nembhard WN, Nichols M, et al. Racial and ethnic disparities in the provision of epidural analgesia to Georgia Medicaid beneficiaries during labor and delivery. Am J Obstet Gynecol. 2004;191(2):456-462. doi:10.1016/j.ajog.2004.03.005

12. Glance LG, Wissler R, Glantz C, Osler TM, Mukamel DB, Dick AW. Racial differences in the use of epidural analgesia for labor. Anesthesiology. 2007;106(1):19-25; discussion 6-8. doi:10.1097/ 00000542-200701000-00008

13. Toledo P, Eosakul ST, Grobman WA, Feinglass J, Hasnain-Wynia R. Primary spoken language and neuraxial labor analgesia use among hispanic medicaid recipients. Anesth Analg. 2016;122(1):204-209. doi:10.1213/ANE.0000000000001079

14. Morris T, Schulman M. Race inequality in epidural use and regional anesthesia failure in labor and birth: an examination of women's experience. Sex Reprod Healthc. 2014;5(4):188-194. doi:10.1016/j. srhc.2014.09.006

15. Butwick AJ, Blumenfeld YJ, Brookfield KF, Nelson LM, Weiniger CF. Racial and ethnic disparities in mode of anesthesia for cesarean delivery. Anesth Analg. 2016;122(2):472-479. doi:10.12 13/ANE.0000000000000679

16. Goldberg AB, Cohen A, Lieberman E. Nulliparas' preferences for epidural analgesia: their effects on actual use in labor. Birth Berkeley Calif. 1999;26(3):139-143. doi:10.1046/j.1523-536x. 1999.00139.x

17. Ochroch EA, Troxel AB, Frogel JK, Farrar JT. The influence of race and socioeconomic factors on patient acceptance of perioperative epidural analgesia. Anesth Analg. 2007;105(6):1787-1792. doi:10. 1213/01.ane.0000290339.76513.e3

18. Hueston WJ, McClaflin RR, Mansfield CJ, Rudy M. Factors associated with the use of intrapartum epidural analgesia. Obstet Gynecol. 1994;84(4):579-582.

19. Liu N, Wen SW, Manual DG, Katherine W, Bottomley J, Walker MC. Social disparity and the use of intrapartum epidural analgesia in a publicly funded health care system. Am J Obstet Gynecol. 2010;202(3):273.e1-273.e8. doi:10.1016/j.ajog.2009.10. 871

20. Orejuela FJ, Garcia T, Green C, Kilpatrick C, Guzman S, Blackwell S. Exploring factors influencing patient request for epidural analgesia on admission to labor and delivery in a predominantly latino population. J Immigr Minor Health. 2012;14(2):287-291. doi:10.1007/s10903-011-9440-2

21. Yurashevich M, Carvalho B, Butwick AJ, Ando K, Flood PD Determinants of women's dissatisfaction with anaesthesia care in labour and delivery. Anaesthesia. 2019;74(9):1112-1120. doi:10.11 11/anae. 14756

22. Torres CA, Thorn BE, Kapoor S, DeMonte C. An examination of cultural values and pain management in foreign-born spanish-speaking hispanics seeking care at a federally qualified health center. Pain Med. 2017;18(11):2058-2069. doi:10.1093/ $\mathrm{pm} / \mathrm{pnw} 315$

23. Miles MB, Huberman AM. Qualitative Data Analysis: An Expanded Sourcebook. 2nd ed. Thousand Oaks: Sage Publications; 1994.

24. Ethnograph: the Ethnograph home page. Available from: http://www. qualisresearch.com/default.htm. Accessed March 7, 2020.

25. Leap N A midwifery perspective on pain in labour; 1997.

26. Dick-Read G. Childbirth Without Fear: The Principles and Practice of Natural Childbirth. 2nd ed. London: Pinter \& Martin; 2013.

27. Gaskin IM. Spiritual Midwifery. Rev ed. Summertown, TN: Book Pub. Co; 1977. 
28. England P, Horowitz R. Birthing from Within: An Extra-Ordinary Guide to Childbirth Preparation. Albuquerque: Postera Press; 1998.

29. Jouppila R, Jouppila P, Karlqvist K, Kaukoranta P, Leppäluoto J, Vuolteenaho O. Maternal and umbilical venous plasma immunoreactive beta-endorphin levels during labor with and without epidural analgesia. Am J Obstet Gynecol. 1983;147(7):799-802. doi:10.1016/ 0002-9378(83)90042-x

30. Brinsmead M, Smith R, Singh B, Lewin T, Owens P. Peripartum concentrations of beta endorphin and cortisol and maternal mood states. Aust N Z J Obstet Gynaecol. 1985;25(3):194-197. doi:10. 1111/j.1479-828X.1985.tb00642.x

31. McLean M, Thompson D, Zhang H-P, Brinsmead M, Smith R. Corticotrophin- releasing hormone and $\beta$-endorphin in labour. Eur $J$ Endocrinol. 1994;131(2):167-172. doi:10.1530/eje.0.1310167

32. Downe S. Normal Childbirth: Evidence and Debate. London: Elsevier Health Sciences UK; 2008. Available from:: http://www. 123library.org/book_details/?id=30093. Accessed February 22, 2020.

33. Halls K. Maternal satisfaction regarding anaesthetic services during childbirth. Br J Midwifery. 2008;16(5):296-301. doi:10.12968/ bjom.2008.16.5.29190

34. Callister LC, Khalaf I, Semenic S, Kartchner R, VehvilainenJulkunen K. The pain of childbirth: perceptions of culturally diverse women. Pain Manag Nurs. 2003;4(4):145-154. doi:10.1016/S15249042(03)00028-6

35. Lundgren I, Dahlberg K. Women's experience of pain during childbirth. Midwifery. 1998;14(2):105-110. doi:10.1016/S0266-6138(98) 90007-9
36. Halldorsdottir S, Inga Karlsdottir S. Journeying through labour and delivery: perceptions of women who have given birth. Midwifery. 1996;12(2):48-61. doi:10.1016/S0266-6138(96)90002-9

37. Niven CA, Murphy-Black T. Memory for labor pain: a review of the literature. Birth. 2000;27(4):244-253. doi:10.1046/j.1523-536x.2000. 00244.x

38. McCrea H, Wright ME, Stringer M. Psychosocial factors influencing personal control in pain relief. Int J Nurs Stud. 2000;37(6):493-503. doi:10.1016/S0020-7489(00)00029-8

39. Christensen-Szalanski JJJ. Discount functions and the measurement of patients' values: women's decisions during childbirth. Med Decis Making. 1984;4(1):47-58. doi:10.1177/0272989X8400400108

40. Kpéa L, Bonnet M-P, Le Ray C, Prunet C, Ducloy-Bouthors A-S, Blondel B. Initial preference for labor without neuraxial analgesia and actual use: results from a national survey in France. Anesth Analg. 2015;121(3):759-766. doi:10.1213/ANE.0000000000000832

41. Lally JE, Murtagh MJ, Macphail S, Thomson R. More in hope than expectation: a systematic review of women's expectations and experience of pain relief in labour. BMC Med. 2008;6(1):7. doi:10.1186/ 1741-7015-6-7

42. Togioka BM, Seligman KM, Werntz MK, Yanez ND, Noles LM, Treggiari MM. Education program regarding labor epidurals increases utilization by hispanic medicaid beneficiaries: a randomized controlled trial. Anesthesiology. 2019;131(4):840-849. doi:10.1097/ALN.0000000000002868

\section{Publish your work in this journal}

The International Journal of Women's Health is an international, peerreviewed open-access journal publishing original research, reports, editorials, reviews and commentaries on all aspects of women's healthcare including gynecology, obstetrics, and breast cancer. The manuscript management system is completely online and includes a very quick and fair peer-review system, which is all easy to use. Visit http://www.dovepress.com/testimonials.php to read real quotes from published authors. 